\title{
Challenges faced by mental health patients and role of community
}

\author{
Hafiza Saadia Shareef ${ }^{1}$ and Zainab Shafaat ${ }^{2 *}$
}

1. Department of International Relations, Faculty of Pakistan Studies, Lahore Garrison University, Lahore-Pakistan

2. Department of Fashion Design Technology, Faculty of Fashion Design, Punjab Tianjin University of Technology, Lahore-Pakistan

*Corresponding author's email: zainab.shafaat1@gmail.com

Citation

Hafiza Saadia Shareef and Zainab Shafaat. Challenges faced by mental health patients and role of community. Pure and Applied Biology. Vol. 10, Issue 4, pp1249-1257. http://dx.doi.org/10.19045/bspab.2021.100131

\begin{tabular}{llll}
\hline Received: 01/11/2020 & Revised: 02/02/2021 & Accepted: 08/02/2021 & Online First: 11/02/2021 \\
\hline \hline
\end{tabular}

\section{Abstract}

People suffering from mental illnesses face numerous socio psychological challenges. All around the world there are policies related to proper care for people with any kind of mental illness. Improving the quality of care would positively affect behavior and intellectual abilities of patients with mental disabilities. Mental health illnesses are found in all societies but all patients do not receive effective treatments in this regard. This study was conducted to gather information about challenges faced by mental health patients and factors that support their treatment. Present research will help in increasing public awareness about various challenges of such patients and play a mediating role in filling gap regarding awareness among care givers about patients. Findings of our research also adds to the literature related to this field. For this purpose a sample of 40 participants was selected, who have faced any form of mental illness through purposive sampling technique. We found that people suffering from mental health illnesses face many social problems due to lack of awareness, such as social isolation, discrimination and identity stigmas. Challenges related to stress and depression can be avoided by providing necessary therapies such as psychotherapies, music therapies, sound therapies, professional counseling session and other interventions in the field of clinical psychology. Although many psychotherapies are available in the field to cope with mental problems but their benefit highly depend on the support of family, friends and community at large.

Keywords: Behavior; Challenges; Disabilities; Issues; Mental; Social

\section{Introduction}

Mental illnesses are seen all over the world [1]. According to an estimate one in every 33 people occurs to be facing mental disability [2]. World Health Organization gives an estimate that $10 \%$ of the world's total population has certain mental health illnesses, whereas $1 \%$ undergoes severe mental illness [3]. Throughout the history, various cultures, and communities have individuals who include people with sub- normal mental functioning. Such people have compromised ability to cope with their daily routine such as ordinary schooling and face difficulties in maintaining themselves in the community [4].

Most people around the world cannot treat their mental illness either because of less resources and care for the patient with mental illness. To provide proper care to the patients of mental illness, both problems should be eliminated from our societies. Mental health 
is the most crucial thing in one's life. It is basically mental wellbeing of an individual. People with sound mental health can achieve in life, solve everyday problems, accomplish routine tasks and experience better social life [2]. Mental illness could be the result of a psychological or physiological trauma or it could be hereditary or inborn as well [4]. Timely diagnosis and proper treatment can help in curing disability.

\section{Mental disability}

Mental disability is actually a disorder related to mind cognition, problem solving and decision making processes. Family, friends and community face several difficulties due to such condition of an individual. Mental disabilities affect social behavior and therefore impair social adjustment of an individual. A definition of the term states that "Mental disabilities encompass a wide range of profoundly different conditions and notably two sets of conditions, psychiatric/psychosocial disabilities, and intellectual disabilities. Both sets, and many individual conditions, are distinct in their causes and effects" [5]. Whereas according to another definition "mental retardation, or disability is characterized by significant limitations both in intellectual functioning and in adaptive behavior as expressed in conceptual, social, and practical adaptive skills" [6].

\section{Challenges faced by mentally disable people}

Studies have revealed several psychosocial problems faced by people suffering from mental illness. Feelings such as frustration, shame and guilt, social exclusion, stigma, discrimination, unequal treatment and stereotyping are most common dilemmas. Individuals who are psychologically challenged are very sensitive to being rejected and are easily hurt due to mocking or tease [7].

People suffering from mental illnesses do not suffer alone, their families' also face numerous problems. Research has shown that their families fell hopelessness, frustration and shame due to their family member with mental illness. This negative association can be due to lack of social awareness that such person can become self-supportive in case of proper training, care, assistance, treatment and encouragement. In case of children parents face social, economic, emotional and material challenges while upbringing their mentally challenged children [8]. Public health reformers have pointed out that reciprocal relationship between poverty and disease also elevate mental disabilities. These social determinants of health directly affect our mental health. Poverty, gender discrimination, violence, cultural problems, social discrimination, political issues, armed conflicts, and forced association are also directly linked with problems. In case of untreated mental illness the situation becomes more serious and severe problems related to emotions, behavior, psychological and social wellbeing increases [9].

Impact of community in improvement from mental illness

A healthy community can have positive impact on improvement of mental patients. Several factors contribute in elevating mental health issues such as culture problems, discrimination, employment opportunity and income inequality. A positive role of community can produce lasting effects in the lives of people with mental disabilities. In order to understand the influence of culture and society on mental health, awareness campaigns and training sessions for care givers can play a crucial role. The attitude towards mental illness can be improved by social awareness and positive guidance on community level [9]. Proper social and educational reforms can help in decreasing rate of suicide. Clinical stereotyping should also be avoided by mental health professionals. Today all developed societies are striving to overcome discrimination and 
racism. Discrimination on numerous levels is the main cause of many psycho-social problems in today's global world. Culture and society has a great impact on mental illness as every culture has its way of experiencing and describing their feelings or emotions [6].

Mental problems can also be caused by lack of proper care from friends or family. Negative environment can make a person mentally stressed and tired effecting his mental wellbeing. Cultural norms and social values can also become a reason for mental disability [10]. Every society has set standards of beauty and perfection, due to which anyone who cannot live up to the standard becomes depressed and might face inferiority complex [11]. Stressful conditions contribute to the development of a mental disorder [12]. Our society separates these people whereas the previous studies suggest that interaction can reduce the stigmatized behavior of people.

\section{Problem statement}

Basic purpose of this study was to assess problem and social challenges of mental health patients. As community can plays a vital role in the improvement of mental health patients. The facets of societal behaviors that can potentially play a positive role in improvement of mentally ill patients was focused in this study.

\section{Objectives}

- To identify challenges of people with mental disabilities

- To investigate the role of community in improvement of people with mental disabilities

\section{Research questions}

1. What are the challenges of people with mental disabilities?

2. What is the role of community in improvement of people with mental disabilities?

\section{Materials and Methods}

In this research we used quantitative research method to collect data related to social and psychological challenges of mental health patients. Questionnaire consist of series of questions designed to obtain actual information about mental health. It consisted of 15 items used to analyze mental health of patients. Among these 5 items measured stress and depression related problems of people suffering from mental illness, 3 items analyzed personal relationships, social activities and job related challenges of people suffering from mental illness, 5 items analyzed behavior challenges faced by people suffering from mental illness and 2 items analyzed role of community in improvement of people suffering from mental illness. Our aim was to determine general perceptions about challenges of mental health patients. Purposive sampling technique was used to select sample for data collection. Our sample included people with mental disabilities. 40 people including both males and females with mental disabilities were selected for this research. Being mindful of ethical considerations privacy of information about participants was assured during the research. Prior consent was taken from all participants before filling the questionnaire.

\section{Results}

The (Table 1) shows opinion about challenges faced by people suffering from mental illness due to stress and depression. More than $32 \%$ people said that during the time of stress they do not know where to turn for help, while $25 \%$ people said that they know where to turn for help. More than $30 \%$ people said that during the past week they felt sad and depressed. The opinion about having to cope with stress can make me stronger was scattered as $27.5 \%$ people agreed, $20 \%$ strongly agreed, while $22.5 \%$ disagreed, which is also considerably a larger percentage. $35 \%$ participants agreed and 
$17.5 \%$ strongly agreed that they experience feeling of hopelessness. $42.5 \%$ agreed and
$27.5 \%$ strongly agreed that they feel tired for no good reason.

Table 1. Challenges faced by people suffering from mental illness due to stress and depression

\begin{tabular}{|c|c|c|c|c|c|c|c|c|c|c|c|}
\hline \multirow[t]{2}{*}{$\begin{array}{l}\mathbf{S} \\
\#\end{array}$} & \multirow[t]{2}{*}{$\begin{array}{c}\text { Consent } \\
\text { statement }\end{array}$} & \multicolumn{2}{|c|}{$\begin{array}{c}\text { 1. During the } \\
\text { time of stress } \\
\text { I know where } \\
\text { to turn for } \\
\text { help }\end{array}$} & \multicolumn{2}{|c|}{$\begin{array}{l}\text { 2. During the } \\
\text { past week } \\
\text { have you felt } \\
\text { sad or } \\
\text { depressed } \\
\end{array}$} & \multicolumn{2}{|c|}{$\begin{array}{l}\text { 3. Having to } \\
\text { cope with stress } \\
\text { can make me } \\
\text { stronger }\end{array}$} & \multicolumn{2}{|c|}{$\begin{array}{c}\text { 4. Did you } \\
\text { feel } \\
\text { hopeless }\end{array}$} & \multicolumn{2}{|c|}{$\begin{array}{l}\text { 5. Did you } \\
\text { feel tired out } \\
\text { for no good } \\
\text { reason }\end{array}$} \\
\hline & & $F$ & $\%$ & $f$ & $\%$ & $f$ & $\%$ & $f$ & $\%$ & $f$ & $\%$ \\
\hline 1 & $\begin{array}{l}\text { Strongly } \\
\text { Disagree }\end{array}$ & 1 & 2.5 & 7 & 17.5 & 5 & 12.5 & 1 & 2.5 & 1 & 2.5 \\
\hline 2 & Disagree & 13 & 32.5 & 9 & 22.5 & 9 & 22.5 & 8 & 20.0 & 4 & 10.0 \\
\hline 3 & $\begin{array}{c}\text { Neither } \\
\text { Agree } \\
\text { nor } \\
\text { Disagree }\end{array}$ & 10 & 25.0 & 7 & 17.5 & 7 & 17.5 & 10 & 25.0 & 7 & 17.5 \\
\hline 4 & Agree & 10 & 25.0 & 12 & 30.0 & 11 & 27.5 & 14 & 35.0 & 17 & 42.5 \\
\hline 5 & $\begin{array}{c}\text { Strongly } \\
\text { Agree }\end{array}$ & 6 & 15.0 & 5 & 12.5 & 8 & 20.0 & 7 & 17.5 & 11 & 27.5 \\
\hline & Total & 40 & 100. & 40 & 100. & 40 & 100. & 40 & 100. & 40 & 100.0 \\
\hline
\end{tabular}

The (Table 2) shows opinions about challenges faced by people suffering from mental illness related to personal relationships, social activities and workplace. $25 \%$ participants strongly agreed and $23 \%$ agreed that during the past week their mental health interfered with their personal relationships. Almost 27\% strongly agreed and $25 \%$ agreed with the statement that during the past week their mental health interfered with their ability to get work done or accomplish task. 30\% respondents agreed and $20 \%$ strongly agreed that their physical health or emotional problems interfered with their social activities.

The (Table 3) shows opinion about behavior challenges faced by people suffering from mental illness. Almost $45 \%$ respondents reported that people with mental illness have unpredictable behavior. $40 \%$ respondents reported agreed that if people become mentally ill once, there is increased tendency of facing mental illness again. $45 \%$ participants agreed with the opinion that people with mental illness tend to be violent. More than $40 \%$ people said that they do not express themselves when they felt sad or angry. More than $32 \%$ people said that it is hard to have good friends with mental illness. More than $52 \%$ respondents said that care and support of family and friends is very important as it can help people with mental illness to get rehabilitated. $11 \%$ respondents reported that the best way to help those with mental illness is to recover by letting them stay in community and live a normal, while $13 \%$ strongly disagreed and stressed on the role of rehabilitation centers and training of family and community before letting mentally ill people in main stream (Table 4).

\section{Discussion}

The aim of this study was to identify key social and psychosocial challenges that individuals with mental illness face. Our findings are in line with prior studies. The purpose was to describe role of family and community in treatment of such patients for getting better results. 
Challenges faced by people suffering from mental illness

The results show that key requirements of patients are connected to basic needs such as education, security, health care, socioeconomic support, and positive approach of care givers. There is a great need for support from community and society at large. Problems faced by families of such patients include discrimination, personal relationships and fears for the future. Mental health patients most of the time become heavy burden for the family.

Table 2. Challenges faced by people suffering from mental illness related to personal relationships, social activities and workplace

\begin{tabular}{|c|c|c|c|c|c|c|c|}
\hline \multirow[t]{2}{*}{$\begin{array}{l}\mathbf{S} \\
\#\end{array}$} & \multirow[t]{2}{*}{$\begin{array}{c}\text { Consent } \\
\text { statement }\end{array}$} & \multicolumn{2}{|c|}{$\begin{array}{l}\text { 6. During the past } \\
\text { week your mental } \\
\text { health interfered } \\
\text { your personal } \\
\text { relationship }\end{array}$} & \multicolumn{2}{|c|}{$\begin{array}{l}\text { 7. During the past week } \\
\text { your mental health } \\
\text { interfered with your } \\
\text { ability to get work done or } \\
\text { accomplish task }\end{array}$} & \multicolumn{2}{|c|}{$\begin{array}{c}\text { 8. Your physical } \\
\text { health or emotional } \\
\text { problems interfered } \\
\text { with your social } \\
\text { activities }\end{array}$} \\
\hline & & $f$ & $\%$ & $f$ & $\%$ & $f$ & $\%$ \\
\hline 1 & $\begin{array}{l}\text { Strongly } \\
\text { Disagree }\end{array}$ & 1 & 2.5 & 3 & 7.5 & 5 & 12.5 \\
\hline 2 & Disagree & 5 & 12.5 & 5 & 12.5 & 8 & 20.0 \\
\hline 3 & $\begin{array}{c}\text { Neither Agree } \\
\text { nor Disagree }\end{array}$ & 15 & 37.5 & 11 & 27.5 & 7 & 17.5 \\
\hline 4 & Agree & 9 & 22.5 & 10 & 25.0 & 12 & 30.0 \\
\hline 5 & Strongly Agree & 10 & 25.0 & 11 & 27.5 & 8 & 20.0 \\
\hline & Total & 40 & 100.0 & 40 & 100.0 & 40 & 100.0 \\
\hline
\end{tabular}

Table 3. Behavior Challenges faced by people suffering from mental illness

\begin{tabular}{|c|c|c|c|c|c|c|c|c|c|c|c|}
\hline \multirow[t]{2}{*}{$\begin{array}{l}\mathbf{S} \\
\#\end{array}$} & \multirow[t]{2}{*}{$\begin{array}{c}\text { Consent } \\
\text { statement }\end{array}$} & \multicolumn{2}{|c|}{$\begin{array}{c}\text { 9. People with } \\
\text { mental illness } \\
\text { have } \\
\text { unpredictable } \\
\text { behavior }\end{array}$} & \multicolumn{2}{|c|}{$\begin{array}{l}\text { 10. If people } \\
\text { become } \\
\text { mentally ill } \\
\text { once, they will } \\
\text { easily become } \\
\text { ill again } \\
\end{array}$} & \multicolumn{2}{|c|}{$\begin{array}{l}\text { 11. People } \\
\text { with mental } \\
\text { illness tend } \\
\text { to be violent }\end{array}$} & \multicolumn{2}{|c|}{$\begin{array}{c}\text { 12. When I } \\
\text { am feeling sad } \\
\text { or angry, I } \\
\text { make sure not } \\
\text { to express } \\
\text { them } \\
\end{array}$} & \multicolumn{2}{|c|}{$\begin{array}{l}\text { 13. It is hard } \\
\text { to have good } \\
\text { friends with } \\
\text { mental } \\
\text { illness }\end{array}$} \\
\hline & & $F$ & $\%$ & $f$ & $\%$ & $f$ & $\%$ & $f$ & $\%$ & $f$ & $\%$ \\
\hline 1 & $\begin{array}{l}\text { Strongly } \\
\text { Disagree }\end{array}$ & 2 & 5.0 & 1 & 2.5 & 1 & 2.5 & 5 & 12.5 & 7 & 17.5 \\
\hline 2 & Disagree & 2 & 5.0 & 5 & 12.5 & 4 & 10.0 & 6 & 15.0 & 6 & 15.0 \\
\hline 3 & $\begin{array}{c}\text { Neither } \\
\text { Agree } \\
\text { nor } \\
\text { Disagree }\end{array}$ & 12 & 30.0 & 7 & 17.5 & 5 & 12.5 & 7 & 17.5 & 6 & 15.0 \\
\hline 4 & Agree & 18 & 45.0 & 16 & 40.0 & 18 & 45.0 & 16 & 40.0 & 13 & 32.5 \\
\hline 5 & $\begin{array}{l}\text { Strongly } \\
\text { Agree }\end{array}$ & 6 & 15.0 & 11 & 27.5 & 12 & 30.0 & 6 & 15.0 & 8 & 20.0 \\
\hline & Total & 40 & 100.0 & 40 & 100.0 & 40 & 100.0 & 40 & 100.0 & 40 & 100.0 \\
\hline
\end{tabular}


Table 4. Role of community in improvement of people suffering from mental illness

\begin{tabular}{|c|c|c|c|c|c|}
\hline \multirow[t]{2}{*}{ S } & \multirow[t]{2}{*}{ Consent statement } & \multicolumn{2}{|c|}{$\begin{array}{l}\text { 14. Care and support of family } \\
\text { and friends can help people } \\
\text { with mental illness to get } \\
\text { rehabilitated }\end{array}$} & \multicolumn{2}{|c|}{$\begin{array}{l}\text { 15. The best way to help those } \\
\text { with mental illness is to recover by } \\
\text { letting them stay in community } \\
\text { and live a normal life }\end{array}$} \\
\hline & & $f$ & $\%$ & $f$ & $\%$ \\
\hline 1 & Strongly Disagree & 4 & 10.0 & 13 & 32.5 \\
\hline 2 & Disagree & 3 & 7.5 & 9 & 22.5 \\
\hline 3 & $\begin{array}{c}\text { Neither Agree nor } \\
\text { Disagree }\end{array}$ & 2 & 5.0 & 2 & 5.0 \\
\hline 4 & Agree & 21 & 52.5 & 11 & 27.5 \\
\hline 5 & Strongly Agree & 10 & 25.0 & 5 & 12.5 \\
\hline & Total & 40 & 100 & 40 & 100 \\
\hline
\end{tabular}

\section{Challenges related to stress and depression}

People suffering from mental illness suffer many challenges due to stress and depression. Mental health patients reported that during the time of stress they do not know where to turn for help. Such patients very frequently face stress and depression, while coping with the situation become a hurdle in leading normal life. Emotions of stress and depression also elevate the feelings of unaccomplishment and hopelessness. Our respondents reported that mental health patients often experience being tired without any tedious work. Their other challenges include frustration and felling sadness. Social stigmas and negative behavior towards the individual can cause feeling of insult, harassment, isolation, misunderstandings, and negative stereotypes towards mental health patients.

\section{Challenges related to personal relationships, social activities and workplace}

People suffering from mental illness frequently face problems related to personal relationships, social activities and workplace. It is often reported that their health interferes with personal relationships creating numerous social problems. The problem of social relationships in handling mentally challenged children and adolescents need to be studied. Interpersonal relationships depends upon the quality of care and training of the patient. Un-satisfaction on the part of family members may lead to adjustment issues. Mental health conditions of most patients create a detrimental effect on their family. In most cases mental illness is very hard on a marriage or any relationship. The stress can often reach a crisis level where it damages the relationship of a couple. Mental illness is the most challenging problem of any age. It doesn't only affect the individual but also his parents, siblings, and community. Numerous social stigmas and taboos are related to such health conditions. Families with mentally challenged members are looked down upon by society in general. People with mental illnesses face stigmas of discrimination, as admitting the presence in one's family is a shameful secret. Due to this factor necessary measures are not taken to help these individuals apart from hiding them. But the problem is widely prevailing, as millions of people are suffering that get no professional help, care and training. Such families also start facing economic issues due to heavy cost of treatment and counseling sessions. Some participants reported that money is a major challenge for them. They try to find alternative income source to solve their problems.

In number of cases family complained bitterly about tasks related to the care of their patient. Our findings about challenges for families highlight that family system is 
adversely influenced by mental illness. In the psychological aspect all family members experience stress, and anxiety at certain phase of life. We also found out that mental illness other than childhood disability are more traumatic situation for relatives. Early causes that stress families are inability to express their, feelings, emotions, future life of that individual, and feeling of grief [10]. Mental illnesses also hinder the individual's ability to perform at job place in getting work done. Their mental traumas negatively impacts concentration of mind required for completion of tasks. Owing to these problems their professions career also suffers. In some cases discontinuation of job can also occurs initiating several other problems for both the family and the individual.

\section{Challenges related to behavior}

People suffering from mental illness face serious behavior challenges. Participants reported that unpredictable behavior of mental health patients create social issues. It has been seen that if people become mentally ill once, there is increased tendency of repeatedly facing mental illness. Their compromised ability to cope various social situations requiring emotional intelligence, making them an easy prey for emotional traumas. Emotional traumas can trigger the psychological issues of biological, psychological or environmental origin. Violent behavior of mental health patients cast issues for their social coherence. Social activities also become a challenge as people suffering from such conditions find it difficult to express themselves. Most of the time patients are not able to clearly express themselves when they feel sad or angry.

For them maintaining social relationships is very difficult due to mental health issues. Individuals face problems while having social interaction, due to which they find it difficult to have good friends with mental illness. But social isolation is not an ideal situation for the treatment. Less social awareness about mental health issues is chiefly responsible for social isolation, discrimination and embarrassment of mental health patients and their families. As a study highlighted that society find it difficult to accept a child with mental illness. Less chances of getting recognition from society causes families to go through social stigmas associated with unsuitable behavior patterns displayed by such individuals [7]. Choosing isolation and fear of exposing child in public are other collective effects. Some participants said that their neighbors have isolated them and show false sympathetic gestures instead of care, love and social support. Finding of previous researches also report that family members fear their patient's behavior in public and prefer isolation instead of facing frustration of taking their child in public.

Role of community in improvement of people suffering from mental illness

Community plays a significant role in the improvement of mental health patients. Care and provision of family and friends is very important as it can assist people with mental illness in rehabilitation. The best manner to help mental health patients is to let them recover being a part of community and live a normal life, but the role of rehabilitation centers and training of family and community before letting mentally ill people in main stream is very important. Proper guidance in this regard is required to facilitate the treatment and intervention.

There are many signs of having mental disorders according to disease. In some cases biological, environmental and psychological reasons are the main cause of such disease. Depression, stress, and anxiety are most common psychosocial disorders that lead towards mental illness. Stress is seen as most severe mental illness among youth [11]. Where psychosocial interventions helps in the treatment. Society, family, friends, social worker and psychologist also play an important role for successful results. Culture 
and society has an impact on mental health that may increases the risk of suicide for mentally challenged people. Positive behavior of family members and near relatives can also have a miraculous effect on such patients by making the treatment more fruitful. Mentally challenged people having family members that considered their presence as a positive factor recover speedily from their health issues. Positive perception can seriously improve the management of patients by family.

Family plays a vital role in primary care and support during the treatment phase. After medical diagnosis of mental illness the primary care and support becomes an important responsibility of the family. In a family it is important for other members to care and protect their member having mental illness. Preventions and precautions are also very important in social adjustment of mental health patients to improve public interaction on the whole. Primary care is the day to day care services provided by health care provider which includes general practice, pharmacy and other important services needed by mental health patients. Although providing the mentally ill people with therapy is important but it is also crucial to educate and counsel their family members as they deal with the patient on daily bases. They should know how to deal with the suffering patient. Thus the parents or family members should be properly trained.

Conclusion and Future recommendations From our findings we conclude that people suffering from mental health issues are facing various challenges in our society. These challenges also include financial problem making their social living more difficult. They face problems in understanding and learning due to compromised emotional intelligence. Challenges related to stress and depression can be avoided by providing necessary therapies such as psycho-therapies, music therapies, sound therapies, professional counseling session and other interventions in the field of clinical psychology. Proper training and character building through training sessions with qualified professionals can help mental health patients in achieving balanced personal relationships and participating in social activities in a positive manner. It is very important to build positive thinking process among these individuals to enable their progress in all walks of life. Such individuals are required to be educated regarding workplace ethics and emotional intelligence to smartly manage situations. Training in this aspect can also tend to solve behavior problems of people suffering from mental illnesses. Although many psychotherapies are available in the field to cope with mental problems but their benefit also depends on the support of family, friends and community at large. Lack of proper treatment, medications and care for these patients can produce unpleasant results. The cultural perception that frames a mentally ill person as dangerous human being should also be eradicated. An empathetic and therapeutic environment should be given to the one in need of help. If people having a mental disorder are given an unpleasant environment the disorder can get more severe. Future researches can be conducted on the effectiveness of sound therapy and music therapy in this regard as new interventions are available in this field. It is dire need of the hour to find cost effective therapies to benefit people belonging to all socio economic statuses.

\section{Authors' contributions}

Conceived and designed the experiments: HS Shareef, Performed the experiments: HS Shareef \& Z Shafaat, Analyzed the data: Z Shafaat, Contributed materials/ analysis/ tools: HS Shareef \& Z Shafaat, Wrote the paper: HS Shareef \& Z Shafaat. 


\section{Acknowledgements}

The author is thankful to Lahore Garrison University for supporting in research work especially data collection.

\section{References}

1. Govender N (2002). Attitudes of parents towards their mentally retarded children: A rural Area examination. Doctoral Thesis. University of Zululand.

2. Aslam T, Batool Z, Hashmi N \& Aslam (2011). Socio-psychological problems and needs of mentally retarded children in districts Faisalabad and Islamabad, Pakiatan. The J of Anim \& Plant Sci 21(1): 111-113.

3. Padgett DK (2008). Qualitative Methods in Social Work Research. Sage Publications; New York.

4. Goswami S (2013). The Parental Attitude of Mentally Retarded Children. Global J of Human Soc Sci 13(6).

5. Hunt P \& Mesquita J (2006). Mental Disabilities and the Human Right to the Highest Attainable Standard of Health. Human Rights Quarterly 28: 332-356.

6. Wick-Duffy S, Bradley V \& Buntix, W (2007). The renaming of mental retardation: Understanding the change to the term intel-lectual disability. Intel and Devel Disabi 45: 116-124.
7. Schalock R, Luckasson R, Shogren K, Borth-wick-Duffy S, Bradley V \& Buntix W (2007). The renaming of mental retardation: Understanding the change to the term intel-lectual disability. Intel and Devel Disabil 45(2): 116-124.

8. Moges B (2017). The Study on the Psycho-social Issues and Challenges of Children with Mental Retardation: A Case Study. Sociol and Anthropol 5(3): 254-267.

9. Tekle WC \& Randi OL (2007). Raising a Child with Intellectual Disabilities in Ethiopia: What Do Parents Say. Ame Edu Res Assoc.

10. Hazarika M, Das S \& Choudhury S (2017). Parents' attitude towards children and adolescents with intellectual developmental disorder. Inter J of Child Devel \& Mental Heal 30(1): 11-21.

11. Coleridge P (2000). Disability and culture. Asia Pacific Disabil Rehabil J 1: 21-38.

12. Brooker C (2001). A decade of evidencebased training for work with people with serious mental health problems: progress in the development of psychosocial interventions. J of Mental Heal 10(1): 17-31. 